\title{
Rendering global change problematic: the constitutive effects of Earth System research in the IGBP and the IHDP
}

Ola Uhrqvist and Eva Lövbrand

\section{Linköping University Post Print}

\section{Tweet}

N.B.: When citing this work, cite the original article.

This is an electronic version of an article published in:

Ola Uhrqvist and Eva Lövbrand, Rendering global change problematic: the constitutive effects of Earth System research in the IGBP and the IHDP, 2013, Environmental Politics. Environmental Politics is available online at informaworldTM: http://dx.doi.org/10.1080/09644016.2013.835964

Copyright: Taylor \& Francis (Routledge): SSH Titles http://www.routledge.com/ 
Title: Rendering Global Change Problematic: The Constitutive Effects of Earth System Research in the IGBP and the IHDP

Accepted for publication in Environmental politics (with a few non-substantive edits). Probably in accessible online in September 2013 and in print 2014

Authors: (1) Ola Uhrqvist and (2) Eva Lövbrand

(1) The Department of Thematic Studies: Water and Environmental Studies and the Centre for Climate Science and Policy Research, Linköping University, 60174 Norrköping, Sweden. Corresponding author. Email: ola.uhrqvist@liu.se

(2) The Department of Thematic Studies: Water and Environmental Studies and the Centre for Climate Science and Policy Research, Linköping University, 60174 Norrköping, Sweden.

Abstract: This paper examines efforts to model and predict the future habitability of Earth in three interrelated IGBP and IHDP projects; Global Change and Terrestrial Ecosystems (GCTE), Land Use and Land Cover Change (LUCC), and the Global Land Project (GLP). Drawing upon project documentation and research plans from 1986 to 2012, and ten interviews with researchers involved in project design and implementation, we trace how these projects have represented the problem of global change in the modelling of ecosystem and land use dynamics. The paper illustrates how the imagining of global change as a problem space has been recalibrated as project participants began to bring more aspects of natural and human life in their computations. Hence, a top-down gaze informed by atmospheric physics and predictable cause-effect relationships has over time given way for a more complex Anthropocene imaginary dominated by non-linearity and less predictable thresholds and pathways. Informed by Foucauldian problematics of government, the paper argues that there are intrinsic links between ways of representing and knowing a phenomenon, on the one hand, and ways of acting upon it as to transform it, on the other. Hence, we end by discussing what the qualitative change in how the Earth System is 'rendered problematic' may imply for the practices of environmental science and governance in the years to come.

Key Words: global change, Earth System, Anthropocene, Biopolitics, environmental politics 


\section{Introduction}

Participants at the 2012 Planet under Pressure conference in London, organised by four global change research programmes in preparation for the Rio+20 summit in June the same year, learned that we live in a critical time called the Anthropocene. Since the 1950s the human impress on the natural environment has accelerated to an unprecedented scale, leaving no part of the planet untouched by the modern enterprise. As a consequence, the conference organisers suggested that we have taken a significant step away from the past 10000 years of relative stability, known by geologists as the Holocene, to a more unpredictable and unstable age where humankind has become a geological force influencing the very dynamics and functioning of Earth itself (Brito and Stafford Smith 2012). This daunting image of a planet fully dominated by human activity is neither new, nor innocent. Resting upon a long series of developments in global change research over the past decades, the Anthropocene imagery invoked in London harbours a stewardship ideal with implications for how environmental science and governance is organised and practiced in the $21^{\text {st }}$ century.

The aim of this paper is to understand how this Anthropocene problem space is linked to model developments in two global change research programmes; the International GeosphereBiosphere Programme (IGBP) and the International Human Dimensions Programme of Global Environmental Change (IHDP). Rather than assuming that environmental problems are pre-given, laying there waiting to be revealed, we are in this paper interested in modelling as a central 'calculative practice’ (Miller and Rose 2008) that has constituted global change as a problem of government. To that end our study examines efforts to assess and predict the future habitability of Earth in three interrelated IGBP and IHDP projects; Global Change and Terrestrial Ecosystems (GCTE), Land Use and Land Cover Change (LUCC), and the Global Land Project (GLP). Drawing upon project documentation and research plans from 1986 to 2012, and ten interviews with researchers involved in project design and implementation, we trace how these projects have represented the problem of global change in the modelling of ecosystem and land use dynamics and hereby paved the way for the contemporary Anthropocene imagery.

Central to our analysis is the assumption that there are intrinsic links between ways of representing and knowing a phenomenon, on the one hand, and ways of acting upon it as to 
transform it, on the other (Miller and Rose 2008, p. 15). Although research practices in programmes such as IGBP and IHDP may seem detached from the world of environmental politics, we argue that the process of rendering problems thinkable is a highly political task that shapes the imagining of appropriate response strategies. By approaching model developments in the GCTE, LUCC and GLP projects as 'problematizing activities' (Dean 1999, p. 27) that (re)produce certain assumptions about the nature and dynamics of the system studied, we thus seek to interpret how they have constituted global change as a problem to be addressed and rectified and what consequences this know-how and expertise has in forms of political argument. Inspired by Michel Foucault's analytical efforts to uncover the emergence of expert knowledges and techniques tied to the invention of the population as a problem of government in early modern Europe (Foucault 1998), we turn attention to modelling as an important calculative practice developed to understand, diagnose and act upon the terrestrial components of 'the Earth System'.

Our analysis is organised as follows. After a brief introduction to Foucauldian 'problematics of government' which form the conceptual basis for our analysis, we trace how the problem of global change informed the mandates and institutional set-up of the IGBP and the (I)HDP in the 1980s. As a second step we examine how these two international science programmes operationalized their research agendas in the GCTE, LUCC and GLP projects respectively. Although these projects only represent a limited part of the IGBP and the IHDP efforts to assess and predict the human impress on the natural environment, they are interesting since they effectively illustrate how the imagining of global change as a problem space has been recalibrated as project participants began to bring more aspects of natural and human life into their model computations. Hence, a top-down gaze informed by atmospheric physics and predictable cause-effect relationships has over time given way for a more complex Anthropocene imaginary dominated by non-linearity and more unpredictable thresholds and pathways. In the final section we discuss what this qualitative change in how global change is 'rendered problematic' may imply for the practices of environmental science and governance in the years to come. 


\section{Government as a problematising activity}

Since the late 1970s when Michel Foucault launched the concept 'governmentality' (Foucault 1991, 2008), a growing scholarship has asked how thought is linked to the government of human conduct. Although far from a unified theory, governmentality studies share a common concern for critically examining the role of knowledge production in the formation of modern governmental practices (Rose-Redwood 2006, p. 469). A central assumption underpinning this scholarly tradition is that problems of government do not fall from the sky or emerge ready formed from social practice. As outlined by Burchell et al. (1991, p. x, our italics), 'they are things that have had to be - and which have been - invented.' Rose and Miller (1992) therefore talk about government as a problematizing activity. 'The ideals of government are intrinsically linked to the problems around which it circulates, the failings it seeks to rectify, the ills it seeks to cure' (Rose and Miller 1992, p. 182). Hence, in order to understand the mentalities and machinations of modern government, they suggest that we first have to address the knowledge claims and means of calculation that render 'objects of government thinkable in such a way that their ills appear susceptible to diagnosis, prescription and cure by calculating and normalizing intervention’ (Rose and Miller 1992, p. 183).

Foucault himself devoted a great deal of attention to the forms of knowledge and expertise that emerged with the constitution or invention of 'the population' as a problem of government in the late $18^{\text {th }}$ century Europe (Foucault 2008). His account of biopolitics, or the politics of life (Foucault 1998, p. 139), refers to a set of governmental practices 'concerned with matters of life and death, with birth and propagation, with health and illness, both physical and mental, and with the process that sustain or retard the optimization of the life of a population' (Dean 1999, p. 99). For Foucault biopolitics marked 'the threshold of modernity' (Foucault 1998, p. 143) and refers a new era of governmentality that redefined government from the previous exercise of sovereign power over a territory to a detailed administration of the people living on that territory. This administration of 'the social body' is closely related to the development of new areas of knowledge and expertise that made it possible to gain control over the actual conditions of life, and disciplinary mechanisms that restrict what individual and collective identities can do, be or indeed become. 
In this paper we tap into the literature that has extended Foucault's biopolitical analysis to the environment in which human populations live and upon which they depend. In the late 1990s Rutherford, for instance, suggested that ecology and environmental governance can be regarded as an expression of biopolitics, 'as these originate in, and operate upon, the same basic concerns for managing the "continuous and multiple relations” between the population, its resources and the environment' (Rutherford 1999, p. 45). In a similar vein Luke (1995) interprets environmental governance arrangements as an extension of the biopolitical optimisation of life to the entire planet. To save the global environment, and hereby sustain modern civilisation, it is both necessary to develop 'eco-knowledges' that enable a continuous monitoring, prediction and control over the planetary resource base, and to introduce new parameters of 'enviro-discipline' that seek to foster good ecological citizens capable of subordinating their desires to the common environmental good (Luke 1995). While Luke and others have offered a distinct take on how nature has been governmentalized since the rise of modern environmentalism in the 1970s, this paper is more open-ended. Rather than assuming that the IGBP and IHDP efforts to assess the future habitability of Earth are informed by a particular governmental rationality, we trace the shifting understandings of global change they rest upon and give rise to.

Following Miller and Rose (2008, p. 14), we note that the construction of a field of problems often is a slow and contingent process that involves different agents in different sites, in different ways. Just as the 'entry of life into history' (Foucault 1998, p. 141) in 18th century Europe rested upon developments in diverse fields of knowledge such as modern biology, agricultural sciences, public health and medicine, we will in the following illustrate how the recent extension of biopolitical concern to the entire planet is linked up with historically situated developments in the broad and diverse field of global change research. While the resulting representation of the Earth System as an object of government appears more provisional than what scholars such as Luke and Rutherford previously have suggested, it is by no means neutral. As proposed by Lemke (2002, p. 55), knowledge is an element of government itself which helps to create a discursive field in which exercising power is rational. Hence, to analyse mentalities of government is to analyse political knowledge; i.e. how thought produces the governed reality and hereby directs the ways we act upon it. 
Uhrqvist Lövbrand, Rendering Global Change Problematic - accepted for publication in EP

\section{Rendering global change problematic}

The Anthropocene concept was coined in the wake of the new millennium to capture the quantitative shift in the relationship between the humans and the global environment (Crutzen and Stoermer 2000). The term suggests that the rapid expansion of humankind in numbers and per capita exploitation of Earth's resources during the modern industrial era has pushed the Earth into a new geological époque that may very well threaten the biogeophysical foundations of contemporary civilization (Crutzen 2002). While this imagining of an age fully dominated by human activity has a long and complex history that dates back to the $19^{\text {th }}$ century (see Steffen et al. 2011a), it is hard to separate from international efforts to coordinate the scientific study of global change. The formation of the International Geosphere-Biosphere Programme: A Study of Global Change (IGBP) in 1986 represents a key step in that direction.

The mandate for the IGBP was first outlined in 1983 and further explored during an international symposium organised by the International Council of Science (ICSU) in 1984. At this meeting leading earth scientists from North America and Europe concluded that time had come to develop a new research paradigm that may 'lay the groundwork for an integrated future attack on the problem of global change' (Malone 1985, p. x). Inspired by the progress in international science coordination made during the International Geophysical Year (IGY) in 1957-58, the IGBP was primarily designed to foster disciplinary integration. In contrast to previous scientific efforts to understand the atmosphere, biosphere and hydrosphere as discrete spheres with their own internal dynamics, the promise of this new research programme was to bring all these findings together into an integrated understanding of the ‘total Earth System' (IGBP 1986, p. 1). Such a 'truly global study' was portrayed as a necessary precondition for the reliability of warnings of global change and for a rational management of the Earth's resources (IGBP 1986, p. 2). Hence, beyond describing and understanding the physical, chemical and biological processes that regulate the Earth System, this new research programme was designed to analyse likely future changes in this system and how human perturbations will affect ‘the future habitability of Earth’ (IGBP 1986, p. 5).

When the IGBP was founded at the 21st General Assembly of ICSU in 1986, the programme was primarily envisioned as a collaborative network for the biogeochemical sciences. Although social scientists participated actively in the planning process (Rosswall 2009), their 
contribution to the study of global change was not formally integrated into the programme activities. Instead the International Federation of Institutes for Advanced Study (IFIAS), the United Nations' University (UNU) and the International Social Science Council (ISSC) jointly planned a parallel social science programme in 1987 called 'Human Response to Global Change'. However, in the 1980s the environmental social science community was less coordinated than their natural science peers and the programme failed to gain momentum. Instead the ISSC and UNESCO launched 'the Human Dimensions Programme on Global Change' (HDP) in 1990. Also this programme proved to be a slow starter and weak social science partner to the IGBP. As explained by Jäger (2012), the HDP suffered from limited resources, lack of focus and policy orientation. As a consequence ICSU decided to step in as co-sponsor and in 1996 the programme was redubbed 'the International Human Dimensions Programme on Global Environmental Change’ (IHDP).

In the following sections we examine how the IGBP and the HDP/IHDP operationalized their research agendas and hereby stabilised global change as a problem to be rectified. In particular we ask how efforts to predict the future habitability of Earth at the intersection of these two programmes 'brought life' to Earth System models and hereby changed the initial imagining of Earth System dynamics.

\section{The entry of life into Earth System models}

Already in 1986, the IGBP planning group envisioned that the development of Earth System models would function as the central unifying activity of the programme. By providing ' $a$ common lexicon if not a single language for all the sciences', computer modelling was expected to guide the IGBP's observing systems and experiments (IGBP 1986, p. 9). The primary project charged with this task was the Global Analysis, Integration and Modelling Task Force (GAIM), and after 2004, Analysis, Integration and Modelling of the Earth System (AIMES). While GAIM and AIMES held the promise of making inconsistent, temporarily brief, and geographically discrete data of the Earth's biogeochemical processes function as 'global' by integrating, completing and gridding them (Edwards 2001, p. 62), the process of bringing diverse disciplinary knowledge to bear on global models proved to be more contested and contingent in practice. 
Global Change and Terrestrial Ecosystems (GCTE), one of the initial core projects of the IGBP spanning 1992-2003, illustrates the challenges facing scientists feeding terrestrial data into the integrated Earth System models. The GCTE was designed to predict how terrestrial ecosystems respond to the forces of global change and to determine how these terrestrial effects lead to feedbacks to the atmosphere and the physical climate system (Walker and Steffen 1996). To that end the project was divided into four focus areas that sought to 1) understand how primary ecosystem processes respond to changes in atmospheric CO2, 2) to model this complex suite of responses and impacts to predict changes in ecosystem structure and composition, 3) to predict the impacts of global change on agricultural systems, livestock production, forestry and soils, and 4) from 1994 to study the role of ecosystem complexity in multi-species agriculture (ibid). However, to gear the work of ecologists to the needs of climate modelling proved challenging. Kwa (2005) describes the GCTE as a stage on which conflicts and tensions between different scholarly traditions played out.

A central challenge had to do with the static representation of the terrestrial biosphere within the IGBP modelling community at the time. In the parallel IGBP project 'Biospheric Aspects of the Hydrological Cycle' (BAHC), Soil-Vegetation-Atmosphere-Transfer (SVAT) models were employed to simulate how vegetation affects the climate by modifying the energy, momentum, and hydrologic balance of the land surface. By keeping physiological ecosystem properties (e.g. Leaf Area Index) constant and neglecting the effects of $\mathrm{CO} 2$ on the structure of vegetation, these early SVAT models failed to account for the dynamic nature of living matter and instead portrayed the biosphere as a 'uniform entity (green-slime or big-leaf model) that exchanges carbon, water, and energy with the atmosphere without considering individual species' (Chapin and Shaver 1996, p. 822). This static ecosystem imagery is effectively illustrated by the famous Bretherton diagram of the Earth System (see Fig 1). The diagram, which portrays the Earth System as a relatively simple 'physical machine', was published in 1986 by NASA's Earth System Science Committee chaired by Francis Bretherton and frequently reused by the IGBP during its first decade. The diagram signals the relatively peripheral and passive role assigned to living matter in the IGBP's early Earth System models. 
Uhrqvist Lövbrand, Rendering Global Change Problematic - accepted for publication in EP

- $\quad$ Insert Fig 1 somewhere here -

The GCTE efforts to develop dynamical models of global vegetation for incorporation in General Circulations Models (GCMs) of the Earth's climate system (IGBP 1992, p. 31) represent an important step away from this mechanistic imaginary. Drawing upon previous initiatives to model the geographical consequences to vegetation structure and function of a changing climate (Prentice 1989), the project upgraded the expertise of ecologists and began to confront ecological complexity head on (Walker and Steffen 1996). Nonetheless, in order to feed in relevant data to GCMs, the GCTE participants had to adjust to the space-time scales of atmospheric modellers (IGBP 1988, p. 23-24). At this point in time the finest resolution expected for GCMs, within 'a foreseeable future', were grid cells of $1^{\circ} \times 1^{\circ}(111 \times 111 \mathrm{~km}$ at the equator), while the patches relevant to ecologists ranged from below $100 \mathrm{~m}^{2}$ up to $10 \mathrm{~km}^{2}$ (IGBP 1990, p. 6). As explained by Mooney (1996, p. 13), this spatial inconsistency required ecologists to develop an understanding of what controls the exchanges of resources, such as radiation, energy, water, carbon and nitrogen, of entire ecosystems. Many ecologists were uncomfortable with the GCTE efforts to model the physiology or 'metabolism' of entire ecosystem units. As explained by Kwa (2005, p. 932); '(s)caling up from a forest to a continent involves a process of abstraction, which may lead to the loss of the very content of ecology.'

To overcome this problem, the Dynamic Global Vegetation Models (DGVM) employed by the GCTE introduced a hierarchical three level structure that allowed 'the global' to be broken down to the $1^{\circ} \times 1^{\circ}$ resolution of the 'grid'. As a consequence, ecological dynamics could be located and calculated on a 'patch' scale $\left(<100 \mathrm{~m}^{2}\right)$ (IGBP 1990, p. 6, see also Prentice 1989) and hereby better account for spatial diversity and ecological complexity. This adjustment of modelling practices to the needs and expertise of ecologists opened up for a rethinking of the 'driver-response-impact' chain of reasoning that had informed the project's initial representation of ecosystem responses to global change (IGBP 1997, p. 25). In 1995 the GCTE and GAIM convened a joint workshop to explore how to better account for ecosystem disturbances such as land use, insects and fire in dynamic vegetation models. Model simulations had already illustrated that the terrestrial biosphere does not react to disturbance in a slow and linear fashion, but rapidly and with non-linear results (IGBP 1992, p. 37, 
Gardner et al. 1996). Hence, the workshop made explicit that modelling ecosystems as dynamic required the skill to move from a parameterization of disturbances to models based on process-level understanding (IGBP 1996, p. 7). Even if such 'general disturbance models' proved difficult to operationalize and hereby failed to inform the IGBP's Earth System modelling practices in a more general sense (Betts et al. 1997), they challenged the initial topdown representation of atmosphere-biosphere interactions, organised around clear cause and effect chains, and opened up for a more complex Earth System imaginary dominated by nonlinear interactions and feedbacks.

When approaching living matter as a complex component of the Earth System and a driver of global change in its own right, a new understanding of the Earth's habitability also emerged. The terrestrial biosphere could no longer be accounted for as a static pool of renewable resources ‘to be exploited judiciously and hopefully never depleted' (Luke 2009, p. 130), but appeared increasingly unpredictable. By re-problematizing how ecosystem processes interplay with forces of global change, the discipline-transcending modelling practices of the GCTE hereby paved the way for a less static and mechanistic representation of the problem of global change. In order to better understand and predict long-term changes to this dynamic system, the project also pointed at the need to introduce human activity and adaptability to the Earth System equation (Leemans and Zuidema 1995).

\section{Bringing humans on board}

According to Rutherford (1999), one of the central themes of $20^{\text {th }}$ century environmental discourse has been how to manage populations and recourses in relations to their natural environments. The rising concerns for the Earth's carrying capacity in the 1970s and 80s produced a whole new domain for the 'biopolitical administration of life' (Rutherford 1999, p. 56). Although the overall rationale for the IGBP was to understand the course and causes of human-induced global change, the programme was primarily designed to assess the 'natural background of change' on which human activities are imposed (IGBP 1986, p. 1). It would take until the mid-1990s before 'the human' was incorporated as a dynamic component in its own right in Earth System models. An important step in that direction was taken by the Land 
Use/Land Cover Change (LUCC) project developed in collaboration between the IGBP and the HDP/IHDP from 1991 to 2005.

The LUCC project emerges as an ambitious interdisciplinary project that set out to understand both the human and the biosphysical forces that shape land use and land cover change on global scales. To that end LUCC reached out to a broader scientific community than the parallel GCTE project, spanning the physical, spatial and social sciences (Lambin and Geist 2006). Although the interdisciplinary collaboration within GCTE had produced a more dynamic understanding of the feedbacks between the physical climate system and the terrestrial biosphere, Noble (1996) notes that it failed to adequately represent human-driven changes to ecosystem composition and structure. Caught up in the 'predictive modelling paradigm' adopted by the vast majority of IGBP scientists, the project was less appealing to the social land use scientists involved in the HDP/IHDP network (Noble 1996, p. 175). In the LUCC project, by contrast, the social sciences played a central role. In order to understand the causes and effects of human land use change, the project engaged cultural geographers, anthropologists and political ecologists in place-based case studies. These qualitative analyses of land use patterns were complemented by space-based observations of the land cover consequences, and integrative models to project future land use/cover change (Lambin and Geist 2006).

However, just as the GCTE project had struggled to make ecologists gear their work to fit the global data sets of GCMs, the LUCC project was faced with the challenge of harmonising the participants' different methodological and theoretical traditions. In order to adequately represent and predict the multi-scale structure of the land-use system, the LUCC modellers had to find ways of linking remotely sensed data on land cover changes at the macro-level with local and micro-scale drivers of land use change (e.g. individual and political land use decisions) (Verburg et al. 2006). To account for this interaction of scales was complex and far from uncontested. For many social scientists involved in the LUCC project the macro-scale made little sense. While changes in land cover can be remotely sensed, the variables of interest to cultural geographers or political ecologists can typically not (e.g. government regulation, land-tenure rules, power asymmetries, processes of globalisation) (Rindfuss and Stern 1998, Turner and Robbins 2008). This problem of scale gave renewed energy to the 
debate on how to best 'socialise the pixel', i.e. how to make remote sensing data more relevant to the social, political and economic scales pertinent to land-use decisions (Geohegan et al. 1998). However, in order to fit social data into land-use models, the LUCC scholars also explored ways to aggregate social categories and causal explanations and hereby 'pixel the social' (ibid).

It is tempting to compare these efforts to 'link people to pixels' with the biopolitical ordering of populations in the early modern European state. The arrangement of populations into single countable items were central tools of modern statecraft that both simplified classic state functions such as taxation and conscription, and enabled new forms of power to emerge (Foucault 1991). Through statistical, demographic and epidemiological instruments, the modern state was able standardise and rationalise 'the social body' and hereby imagine a collection of human beings as a living entity, a population, with a history, development and with possibility of pathology (Foucault 1991, p. 99). While the LUCC project's efforts to 'pixel the social' was a central step in the production of 'the land use system' as a domain of intelligibility, the resulting representation of human agency in the project's land use models gave rise to a great deal of debate. As reported by Noble (1996), most land use models of the early 1990s rested upon a classification of possible human reactions to changed circumstances and some decision model of behaviour. In practice this implied that humans were modelled as well-informed economically rational beings, an assumption challenged by the LUCC project's detailed case study narratives (IGBP-IHDP 1999, Jäger 2012). As suggested by Turner et al. (2004), one of the important contributions of the social sciences to the LUCC project was a deeper understanding of the contextual drivers of, and responses to, land use and land cover change in different locales and regions. '(T)he social sciences have led the way in global change science in demonstrating the need to scale down from global to regional and local if the causes and consequences of global changes are to be understood' (Turner et al. 2004, p. 437-438).

When agent-based modelling was introduced to the LUCC project in the late 1990s, modellers were given the means to better simulate micro-scale drivers such as individual and collective land use decisions. Guided by a limited number of micro-economic assumptions and decision rules, these agent-based models by necessity also restricted the range of possible land-use 
decisions (Verburg et al. 2006). However, supported by detailed case study findings, the LUCC project's land use simulations managed to move beyond some of the simplifications or 'myths' on driving forces of land-cover change, and instead offer more refined understandings of the range of political, institutional and economic factors (e.g. urbanisation, international aid, economic globalisation) affecting human land use decisions and responses (Lambin et al. 2001). As a consequence a new terminology emerged that sought to capture 'the generic qualities of both socio-economic and biophysical drivers as well as the place-based, humanenvironment conditions that direct land-use and land-cover change' (Lambin et al. 2001, p. 267). Rather than speaking of human activity as an external cause of global land cover change, the 2006 LUCC project report represents human activity as an inseparable part of 'the coupled human-environment system' (Scientific Steering Committee of LUCC 2006, p. 174).

The LUCC project's representation of this system as complex and adaptive with multiple feedbacks across scale and time does indeed resonate with the ‘total Earth System' imaginary produced by the IGBP in the mid-1980s. However, by asking 'where, when, how fast and why people change their land' (Reid et al. 2006, p. 160), LUCC opened up for a new research trajectory that placed human agency at the centre of Earth System science. Whereas the GCTE project had sought to better capture the biophysical responses of landscapes to forcing functions arising from global change, the LUCC project paved the way for a disciplinetranscending 'land use science' that held the promise of bringing the human, environmental, and remote sensing sciences together in an comprehensive study of the entire 'land system' (Rindfuss et al. 2004). When accounting for the many feedbacks between socio-economic and biophysical drivers of land use/cover change across time and space, the project added new layers of complexity and non-linearity to the IGBP's and IHDP's Earth System imaginary. The planetary machinery, once envisioned by Bretherton and colleagues, was hereby gradually re-constituted as a domain with 'multiple stable states, and multiple trajectories' (IGBP-HDP 1995, p. 29).

\section{Rethinking global change as an Anthropocene problem}

The rethinking of land system dynamics, and indirectly also the problem of global change, under way in the LUCC project at the turn of the century resonates with developments in the 
IGBP and IHDP communities at large. In July 2001 these two programmes summarised their scientific advancements at the First Global Change Open Science Conference in Amsterdam, co-organised with the World Climate Research Programme (WCRP) and DIVERSITAS. The resulting conference declaration reflects the changing and increasingly complex Earth System imaginaries produced within GCTE and LUCC. In the now famous Amsterdam Declaration on Global Change, signed by the chairs of the IGBP, the IHDP, the WCRP and DIVERSITAS, the Earth System is represented as an integrated, self-regulating and utterly complex system comprised of physical, chemical, biological and human components that interact across time and scale (Moore et al. 2002). While human driven changes to the Earth's land surface, water, atmosphere and biogeochemical cycles are portrayed as the main driver of global change, the declaration suggests that these changes cannot be understood in terms of a simple cause-effect paradigm. When imaging humankind as an integral part of Earth System dynamics, human impacts instead cascade through the system in multidimensional patterns that are difficult to determine and predict (Moore et al. 2002).

This representation of how human and natural processes interplay, born out of detailed empirical studies carried out in sub-projects such as the GCTE and LUCC, rendered global change problematic in new ways. In a time when the natural dynamics of the Earth cannot be separated from human activities, global change emerges as an urgent, unprecedented and potentially irreversible Anthropocene crisis. Informed by Crutzen's and Stoermer's (2000) definition of the Anthropocene outlined in an IGBP newsletter one year earlier, the Amsterdam Declaration depicts humankind as a destructive geological force that has pushed the Earth System outside its normal operating range. Interestingly, however, human agency is in the same text approached as the very source of Earth System renewal. In order to stop the accelerating human transformation of the Earth's environment, the declaration calls for an ethical framework for Earth System stewardship and management (Moore et al. 2002). Resonating with the IGBP planning committee some 15 years earlier, an integrated global change science agenda was here identified as a necessary first step in that direction. However, in contrast to the IGBP's original mandate, the Amsterdam Declaration asked the social sciences to step up and partner with their natural science peers in the quest for global sustainability (ibid). 
In the years following the Amsterdam conference the IGBP and the IDHP were restructured to better reflect this insight and hereby place 'coupled human and environment systems' at the centre of the programmes' research activities (Wasson and Underdal 2002, Ojima et al. 2002). The land science agenda developed for the Global Land Project (GLP) offers a good illustration of this new research ideal. Building upon the lessons learned in GCTE and LUCC, the GLP was developed from 2000 to take the study of the terrestrial component of the Earth System to a new level of integration (GLP 2005). To that end the project brought together the various research communities mobilised in the GCTE and LUCC projects in an integrated analysis of 1) the socio-economic and ecological dynamics of the land system, 2) the consequences of land system change for the provision of ecosystem services and human wellbeing, and 3) sustainable land system pathways (ibid).

Also in this project dynamic modelling has been approached as the integrative grammar that will force 'people from different backgrounds to focus on the same relational and behavioural issues, which may otherwise be confounded by disciplinary terminology and concepts' (GLP 2005). However, consistent with the more complex and non-linear representation of the land system emerging from GCTE and LUCC, the GLP science plan offers a more humble understanding of the prospects for reliable predictions of how people interact with their environment. Although process based modelling of land use and vegetation dynamics remains central to the identification of sustainable land system pathways, the GLP research agenda starts from the ontological assumption that cause and effect relations in the multi-scalar and non-continuous land system are inherently difficult to uncover and predict (GLP 2005). In order to come to grips with these complex and relatively unknown system dynamics, the project has incorporated quantitative and qualitative data into the modelling of multiple spatial and temporal scales, bottom-up and top-down processes at differing levels of abstraction (GLP 2005, p. 7).

In this process distinct ways of knowing and representing global change as a problem of government have begun to emerge. Rather than approaching land use change as a local and temporally fixed phenomenon, the combination of methods and scales employed in the project has fostered an understanding of the land system as a non-continuous and overlapping humanenvironmental domain that links distant places in new 'teleconnected' ways (Seto et al. 2012). 
In a time when agricultural products and technologies are traded and diffused across the global economy, project participants have raised the question whether it at all 'make(s) sense to talk about sustainable land-use at any scale below the global level' (Fragkias et al. 2012, p. 17). Effective land use governance here hinges on a holistic understanding of the many interconnected processes that determine the state of the system at any point in time. At the same time, however, the project's attention to the vulnerabilities, resilience and coping strategies of specific sub-systems has highlighted the temporal pathways and legacies, both ecological and social, of particular places (Reenberg 2011). Two regional land systems that appear to share similar dynamics in short time frames, may react differently to changes due to memories and structures produced by past events. From this vantage point, knowledge of the unique social and ecological history of a region is equally essential for giving advice of future management (ibid. p. 4, see also, Willis and Birks 2006).

The problem space emerging from the Global Land Project is thus one that makes distinctions such as global and local, past and present, natural and human obsolete, and instead calls for a 'truly trans-disciplinary and holistic' understanding of how natural and social processes interact and co-evolve across time and space (GLP 2005). In this new problem space there is no natural background to change against which human perturbations can be assessed. If the natural and social dynamics of the land system cannot be separated, global change instead emerges as a truly Anthropocene problem with multi-scalar and temporal dynamics and consequences.

\section{The biopolitics of global change research}

One of the great innovations in the techniques of power in $18^{\text {th }}$ Century Europe, claims Foucault (1998), was the emergence of 'population' as an economic and political problem. Through the development of different fields of knowledge concerned with human life, biological existence was for the first time in history reflected in political existence and the operation of power at the micro-level of the human body was connected to the regulation of entire populations (Foucault 1998). What does it mean to extend this biopolitical administration of life to the environment and the natural resource base upon which human existence depends? And how may such concerns be linked to research practices of international science programmes such as the IGBP and the IHDP? 
In this paper we have traced how scientific efforts to assess and predict the future habitability of Earth in three interrelated IGBP and IHDP projects have constituted global change as a problem to be addressed and rectified. By integrating knowledge from a diverse set of disciplines in the modelling of ecosystem and land system dynamics, the GCTE, LUCC and GLP projects have demonstrated how human activities are both modifying the structure and function of ecosystems and affecting land cover patterns on global scales. We argue that these efforts to understand the terrestrial dynamics of the Earth System have paved the way for contemporary representations of humankind as a planetary force undermining the natural resource base upon which modern civilisation rests. However, our study also illustrates how the making of global change as a problem space is far from a linear process. At the interface of the vast assemblage of people, theories, experiments and techniques enrolled by the GCTE, LUCC and GLP projects to predict the human impress on the natural environment, the solidity of previous problem formulations have been questioned and new understandings Earth System dynamics have emerged. By introducing more aspects of ecological and human life into Earth System models, the mechanistic imaginary once produced by Bretherton and colleagues has given way for a more complex Anthropocene problem space that grants ecological and social processes central roles in the functioning of Earth itself.

It is naturally difficult to draw any direct links between the research practices in the three IGBP and IHDP projects discussed here, and contemporary efforts to devise strategies for Earth System governance (e.g. Biermann 2007). The political effects of contemporary global change research are neither self-evident, nor predetermined. Foucauldian problematics of government do, however, remind us that governing is an activity that always lays claims to knowledge of the sphere to be addressed. As argued by Rose and Miller (1992, p. 182); '(g)overning a sphere requires that it can be represented, depicted in a way which both grasps its truth and re-presents it in a form in which it can enter in the sphere of conscious political calculation.' Governing is also a problematizing activity. Foucault's analyses of modern European rule taught us that government is 'intrinsically linked to the problems around which it circulates, the failings it seeks to rectify, the ills it seeks to cure' (Miller and Rose 2008, p. 61). Hence, the representation and analysis of a problem cannot be separated from efforts to remedy it. With this assumption in mind, we end by pointing at two different biopolitical 
articulations that we think are embedded in contemporary global change research and hereby may inform the practice of environmental science and governance in the years to come.

At first sight the daunting Anthropocene imaginary produced in projects such as GCTE, LUCC and GLP seems to harbor ideals of planetary management and control. In a time when human activity is eroding the ecological goods and services that underpin our lives, concerns have been raised that the Earth System is approaching a threshold or limit beyond which it can no longer sustain modern civilization (GLP 2005, p. 5). In the 'State of the Planet Declaration', launched during the London Planet Under Pressure conference in March 2012, current threats to water, food, biodiversity and other critical resources are represented as a humanitarian emergency on global scales that requires fundamental transformations of human behavior at individual and aggregated scales. Such transformations should be informed by the planetary and regional boundaries for Earth System processes, that if crossed, could generate unacceptable global change. Since such boundaries only can be determined by a continuous and integrated scientific monitoring of Earth System dynamics, the London Declaration grants international science programmes such as the IGBP and IHDP a central role in the future stewardship of planet Earth (Brito and Stafford Smith 2012).

This articulation of global change as a problem space resonates with Luke’s (1995) dystopian interpretation of how 'eco-knowledges' and practices of 'enviro-discipline' interplay to create conditions for geo-power. The contemporary impulse to map, measure and monitor Earth in terms of stocks, flows and systems here emerges as an expression of Northern expertarchy and eco-manegerialism that allows Earth System experts to set the boundaries for individual and political behavior (Luke 1995). In its extreme articulation, this extension of biopolitical administration of life to the entire planet resonates with proposals to engineer Earth System processes on global scales (see UK Royal Society 2009). Although geoengineering remains a controversial stewardship ideal also in Earth System science circles (Steffen et al. 2011b), the early IGBP imagining of the Earth System as a relatively simple physical machine that can be monitored and predicted does seem to harbor such managerial aspirations.

Interestingly, however, this biopolitical rationality is poorly attuned with the more complex representations of global change as a problem space developed over time in the GCTE, LUCC 
and GLP projects. If the multi-scalar and temporal dynamics of coupled humanenvironmental systems are so complex that they cannot be fully understood or forecasted by science, planetary management or control is no longer within human reach. In order to cope with the unknown thresholds in the Earth System, a less hierarchical and more polycentric governance ideal is instead in the making (GLP 2005, Steffen et al. 2011b). This alternative biopolitical articulation appears more sensitive to the social and ecological circumstances and coping strategies of particular places, and approaches multi-stakeholder involvement as a central element in the development of resilient and sustainable responses to the problem of global change now understood as both non-linear and multi-scalar (GLP 2005). To what extent this more participatory and decentralized governance ideal will inform ongoing efforts to devise strategies for Earth System governance remain an open question. How to best 'navigate the Anthropocene' is still subject to debate (Biermann et al. 2012).

For the purpose of this paper it is enough to note that government always is dependent upon knowledge. Hence, in conclusion we propose that analytical efforts to understand the future direction of Earth System governance should not lose sight of the specific circumstances in which particular problematisations of nature and global change emerge, stabilize and transform.

\section{Acknowledgements}

The authors would like to thank the Linköping University LiU FoAss-programme for financial support, our ten interview respondents for generously sharing their thoughts and experiences with us, and two anonymous reviewers for valuable and challenging comments to a previous version of this manuscript.

\section{Interviews}

Canadell, Joseph, 2009-05-11 Skype

Jäger, Jill, 2009-10-05 and 2012-05-30 Skype

Ingram, John, 2009-09-15, 2012-05-28 Skype

Moore, Berrien., 2012-10-05 Skype

Prentice, Colin, 2012-06-11 Skype 
Uhrqvist Lövbrand, Rendering Global Change Problematic - accepted for publication in EP

Reenberg, Anette, 2011-02-11 phone

Rosswall, Thomas, 2009-09-28 and 2012-10-04 Stockholm,

Steffen, Will, 2009-11-17 and 2012-10-22 Stockholm

Svedin, Uno, 2010-12-13 Linköping

Turner, Bill, 2012-06-13 Skype

\section{References}

Betts, R.A., et al., 1997. Contrasting Physiological and Structural Vegetation Feedbacks in Climate Change Simulations. Nature, 387, 796-799.

Biermann, F., 2007. 'Earth System Governance' as a Crosscutting Theme of Global Change Research. Global Environmental Change, 17 (3-4), 326-337.

Biermann, F. et al., 2012. Navigating the Anthropocene: Improving Earth System Governance. Science, 335, 1306-1307.

Brito, L. and Stafford Smith, M., 2012. State of the Planet Declaration. [online] London: Available from:

http://www.planetunderpressure2012.net/pdf/state_of_planet_declaration.pdf. [Accessed 16 April 2013]

Burchell, G. and Gordon, C., 1991. The Foucault Effect: Studies in Governmentality: With Two Lectures by and an Interview with Michel Foucault. University of Chicago Press.

Chapin, F.S.I. and Shaver, G.R., 1996. Physiological and Growth Responses of Arctic Plants to a Field Experiment Simulating Climatic Change. Ecology, 77 (3), 822-840.

Crutzen, P.J. and Stoermer, E.F., 2000. The “Anthropocene”. Global Change Newsletter, 41, 17-18.

Crutzen, P.J., 2002. Geology of Mankind. Nature, 415, 23.

Dean, M., 1999. Governmentality: Power and Rule in Modern Society. London: Sage. 
Uhrqvist Lövbrand, Rendering Global Change Problematic - accepted for publication in EP

Edwards, P.N., 2001. Representing the Global Atmosphere: Computer Models, Data, and Knowledge about Climate Change. In: C.A. Miller and P.N. Edwards eds. Changing the atmosphere: expert knowledge and environmental governance. Cambridge, Mass.: MIT Press, 31-65.

Foucault, M., 1991. Governmentality. In: G. Burchell and C.M. Gordon eds. The Foucault effect: studies in governmentality. London: Harvester Wheatsheaf.

Foucault, M., 1998. The History of Sexuality Vol. 1: The Will to Knowledge. London: Penguin Books.

Foucault, M., 2008. The Birth of Biopolitics: Lectures at the Collège De France, 1978-79. Basingstoke, NY: Palgrave Macmillan.

Fragkias, M., et al., 2012. Land Teleconnections in an Urbanizing World: GLP Report no. 5. UGEC Report no. 6. Copenhagen and Tempe: GLP and UGEC.

Gardner, R.H., et al., 1996. Climate change, disturbances and landscape dynamics. In B.H. Walker and W. Steffen eds. Global change and terrestrial ecosystems. Cambridge University Press, NY., 149-171.

Geohegan, J., et al., 1998. "Socializing the Pixel" and "Pixelizing the Social" in Land-Use and Land-Cover Change. In D.M. Liverman ed. People and pixels: linking remote sensing and social science. Washington, D.C.: National Academies Press, 51-69.

GLP., 2005. Science Plan and Implementation Strategy. IGBP Report no. 53/IHDP Report no. 19. Stockholm: IGBP.

IGBP., 1986. Global Change Report 1 - the International Geosphere-Biosphere Programme: A Study of Global Change: Final Report of the Ad Hoc Planning Group. Stockholm: IGBP.

IGBP., 1988. Global Change Report 4 - the International Geosphere-Biosphere Programme, a Study of Global Change, IGBP: A Plan for Action. Stockholm: IGBP. 
Uhrqvist Lövbrand, Rendering Global Change Problematic - accepted for publication in EP

IGBP., 1990. Global Change Report 11 - Proceedings of the Workshops of the Co-Ordinating Panel on Effects of Global Change on Terrestrial Ecosystems. Stockholm: IGBP.

IGBP., 1992. Global Change Report 21 - Global Change and Terrestrial Ecosystems: The Operational Plan. Stockholm: IGBP.

IGBP., 1996. Global Change Report 38 - Natural Disturbances and Human Land use in Dynamic Global Vegetation Models. Stockholm: IGBP.

IGBP., 1997. IGBP SCIENCE no.1- the Terrestrial Biosphere and Global Change: Implications for Natural and Managed Ecosystems Synthesis of GCTE and Related Research. Stockholm: IGBP.

IGBP-HDP., 1995. Global Change Report 35, HDP Report 7, Land-use and Land-Cover Change: Science/Research Plan. Stockholm: IGBP.

IGBP-IHDP., 1999. Global Change Report 48/IHDP Report 10 - Land-use and Land-Cover Change (LUCC): Implementation Strategy. Stockholm: IGBP.

Kwa, C., 2005. Local Ecologies and Global Science: Discourses and Strategies of the International Geosphere-Biosphere Programme. Social Studies of Science, 35 (923), 923950.

Lambin, Eric F. and Geist, Helmut., 2006. Land-use and Land-Cover Change Local Processes and Global Impacts. Berlin: Springer.

Lambin, E.F., et al., 2001. The Causes of Land-use and Land-Cover Change: Moving Beyond the Myths. Global Environmental Change, 11 (4), 261-269.

Leemans, R. and Zuidema, G., 1995. Evaluating Changes in Land Cover and their Importance for Global Change. Trends in Ecology \& Evolution, 10 (2), 76-81.

Lemke, T., 2002. Foucault, Governmentality, and Critique. Rethinking Marxism, 14 (3), 4964. 
Uhrqvist Lövbrand, Rendering Global Change Problematic - accepted for publication in EP

Luke, T.W., 1995. On Environmentality: Geo-Power and Eco-Knowledge in the Discourses of Contemporary Environmentalism. Cultural Critique, 31, 57-81.

Luke, T.W., 2009. Developing planetarian accountancy: fabricating nature as stock, service, and a system for green Governmentality. In H. Dahms ed. Nature, Knowledge and Negation, Bingley, UK: Emerald Group, 129-160.

Malone, T.F., 1985. Preface. In T.F. Malone and J.G. Roederer eds. Global Change, Cambridge: ICSU Press, xi-xxi.

Miller, P. and Rose, N.S., 2008. Governing the Present: Administering Economic, Social and Personal Life. Cambridge: Polity Press.

Mooney, H.A., 1996. Ecosystem physiology: overview and synthesis. In B.H. Walker and W.L. Steffen eds. Global change and terrestrial ecosystems, Cambridge University Press NY, 13-19.

Moore, B.I., et al., 2002. The Amsterdam Declaration on Global Change. In W.L. Steffen, et al. eds. Challenges of a changing earth: proceedings of the Global Change Open Science Conference. Amsterdam: Springer, 207-208.

NASA., 1986. Earth System Science - Overview: A Program for Global Change. Washington, D.C.: National Aeronautics and Space Administration.

Noble, I.R., 1996. Linking the human dimension to landscape dynamics. In B.H. Walker and W.L. Steffen eds. Global change and terrestrial ecosystems, Cambridge University Press NY, 173-183.

Ojima, D., et al., 2002. Terrestrial Human-Environment Systems: The Future of Land Research in IGBP II. Global Change Newsletter, 50, 31-34.

Prentice, I.C., 1989. Developing a Global Vegetation Dynamics Model: Results of an IIASA Summer Workshop. Laxenburg, Austria: International Institute for Applied Systems Analysis. 
Uhrqvist Lövbrand, Rendering Global Change Problematic - accepted for publication in EP

Reenberg, A., 2011. Toolbox Options for Conceptualizing Change in Human-Environmental Systems - Pathways, Path Dependency, Legacies, Syndromes and Scenarios. Copenhagen: GLP.

Reid, R.S., et al., 2006. Linking Land-Change Science and Policy: Current Lessons and Future Integration. In E.F. Lambin and H. Geist eds. Land-use and land-cover change local processes and global impacts. Berlin: Springer, 157-172.

Rindfuss, R.R. and Stern, P.C., 1998. Linking remote sensing and social science: The need and the challenges. In D.M. Liverman ed., People and pixels: linking remote sensing and social science. Washington, D.C.: National Academies Press.

Rindfuss, R.R., et al., 2004. Developing a Science of Land Change: Challenges and Methodological Issues. Proceedings of the National Academy of Sciences of the United States of America, 101 (39), 13976-13981.

Rose, N. and Miller, P., 1992. Political Power Beyond the State: Problematics of Government. The British Journal of Sociology, 43 (2), 173-205.

Rose-Redwood, R.S., 2006. Governmentality, Geography and the Geo-Coded World. Progress in Human Geography, 30 (4), 469-486.

Rutherford, P., 1999. The entry of life into history. In É Darier ed. Discourses of the environment. Oxford, UK: Blackwell, 37-62.

Scientific Steering Committee of LUCC., 2006. Conclusion. In E.F. Lambin and H. Geist eds. Land-use and land-cover change local processes and global impacts. Berlin: Springer, 173-176.

Seto, K.C., et al., 2012. Urban Land Teleconnections and Sustainability. Proceedings of the National Academy of Sciences, 109 (20), 7687-7692.

Steffen, W., et al., 2011a. The Anthropocene: Conceptual and Historical Perspectives. Philosophical Transactions of the Royal Society A: Mathematical, Physical and Engineering Sciences, 369, 842-867. 
Uhrqvist Lövbrand, Rendering Global Change Problematic - accepted for publication in EP

Steffen, W., et al., 2011b. The Anthropocene: From Global Change to Planetary Stewardship. AMBIO, 40 (7), 739-761.

Turner, B.L. and Robbins, P., 2008. Land-Change Science and Political Ecology: Similarities, Differences, and Implications for Sustainability Science. Annual Review of Environment and Resources, 33, 295-316.

Turner, B.L., Moran, E.F. and Rindfuss, R.R., 2004. Integrated Land-Change Science and Its Relevance to the Human Sciences. In G. Gutman, et al. eds. Land Change Science. Dordrecht: Kluwer Academic Publishers, 431-447.

UK Royal Society., 2009. Geoengineering the Climate: Science, Governance and Uncertainty. London: The Royal Society.

Verburg, P.H., et al., 2006. Modeling Land-Use and Land-Cover Change. In E.F. Lambin and H. Geist eds. Land-Use and Land-Cover Change. Berlin: Springer 117-135.

Walker, B. H. and Steffen, W. L., 1996. Global Change and Terrestrial Ecosystems. Cambridge University Press, NY.

Wasson, B. and Underdal, A., 2002. Human-Environment Interactions: Method and Theory. Global Change Newsletter, 49, 22-23.

Willis, K.J. and Birks, H.J.B., 2006. What is Natural? The Need for a Long-Term Perspective in Biodiversity Conservation. Science, 314 (5803) 1261-1265. 
Uhrqvist Lövbrand, Rendering Global Change Problematic - accepted for publication in EP

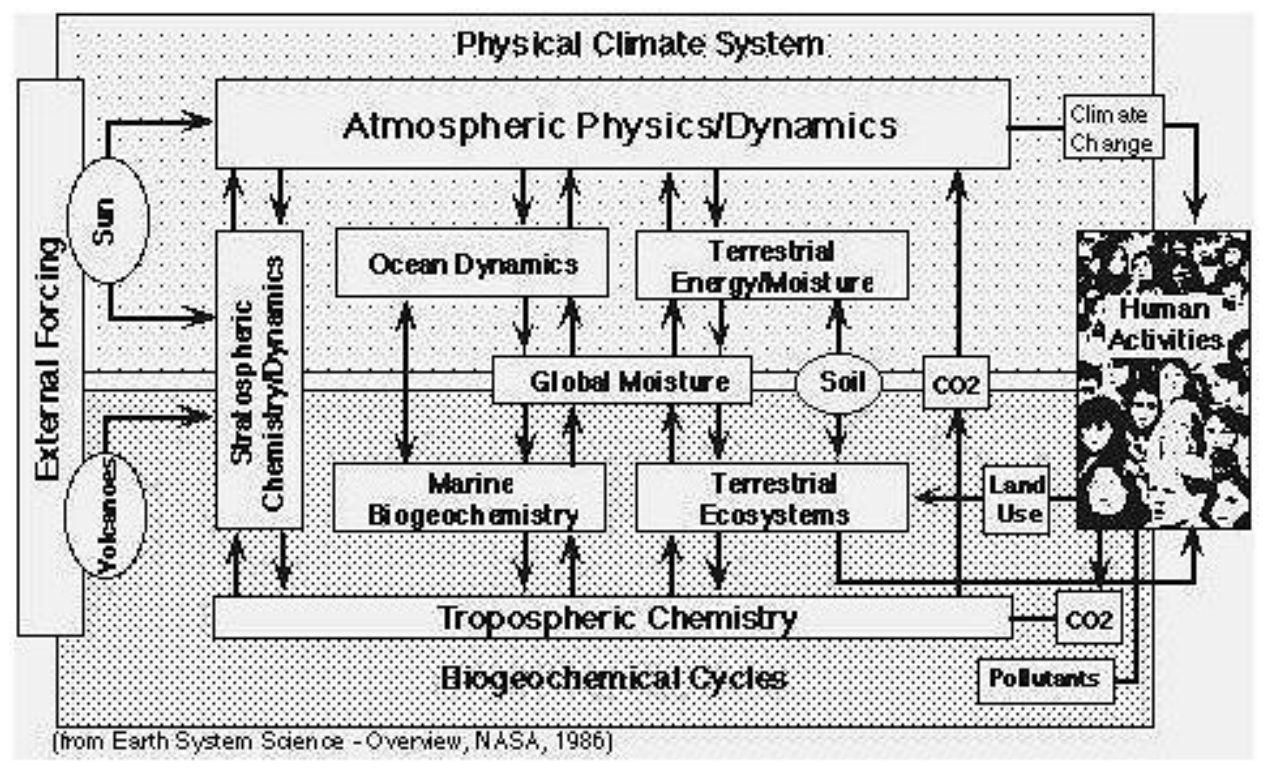

Figure 1: The Bretherton Diagram of the Earth System (NASA 1986). 